\title{
Lactate Metabolism of Isolated, Perfused Fetal, and Newborn Pig Hearts
}

\author{
JOHN C. WERNER AND RAYMOND E. SICARD \\ Division of Pediatric Cardiology, Department of Pediatrics, Rhode Island Hospital, Brown University Program in \\ Medicine, Providence, Rhode Island 02903
}

\begin{abstract}
The role of lactate as an energy substrate in fetal ( 0.9 gestation) and newborn ( 2 day old) hearts was investigated in isolated, perfused hearts. Perfusions were performed with Krebs-Henseleit buffer supplemented with glucose $(5 \mathrm{mM})$ in combination with varying concentrations of lactate. Isolated working heart perfusions, in which the heart ejects the buffer at controlled pressure, were carried out with glucose $(5 \mathrm{mM})$ alone and with glucose $(5 \mathrm{mM})$ and lactate $(5 \mathrm{mM})$ combined. With glucose as sole substrate, lactate was produced by the heart and glucose uptake accounted for approximately two-thirds of oxygen consumption. When both glucose and lactate were provided, lactate accounted for more than $80 \%$ of oxygen consumption and profoundly suppressed glucose uptake. Further investigations using retrograde perfusion through the aorta demonstrated that lactate uptake was consistently observed when exogenous lactate concentrations exceeded $1.25 \mathrm{mM}$. Glucose uptake was suppressed with lactate concentrations as low as $0.5 \mathrm{mM}$ and progressive suppression occurred with increasing lactate concentrations. Fetal and newborn pig hearts utilize lactate as a primary substrate for energy production when lactate concentrations are in the physiological range. (Pediatr Res 22: 552-556, 1987)
\end{abstract}

\section{Abbreviations}

ATP, adenosine triphosphate

BSA, bovine serum albumin

CP, creatine phosphate

CVO, combined ventricular output

ip, intraperitoneal

PCA, perchloric acid

There is extensive evidence to indicate that the primary sources of metabolic energy in the mature heart are fatty acids (1-3). Fatty acids are known to become available to the immature heart shortly after birth due to mobilization of body stores.(4). In the fetal circulation, however, fatty acids are present only in small amounts $(5,6)$. Therefore, it has been assumed that glucose must provide the primary source of metabolic energy for the fetal heart, since fetal, as opposed to adult, tissues are presumed to be relatively dependent on anaerobic metabolism. Nevertheless, there is evidence of net lactate uptake by fetuses as a whole (7, 8 ); the placenta is a rich source of lactate even under aerobic conditions (8). Moreover, one study in intact sheep suggests that

Received April 23, 1987; accepted June 26, 1987

Correspondence and reprint requests John C. Werner, M.D., Department of Pediatrics, Rhode Island Hospital, 593 Eddy Street, Providence, RI 02903. tion. lactate uptake by the fetal heart is sufficient to account for most of oxygen consumption by that organ (5).

In previous studies using isolated, working perfused hearts, exogenous lactate and pyruvate uptake by newborn $(<2$ days old) pig hearts was sufficient to account for all of the oxygen consumption observed when these were the sole substrates provided (9). In contrast, glucose uptake was not adequate to account for all of oxygen consumption, even when provided as the sole exogenous substrate (10). Fatty acid uptake in the same model was reduced in fetal ( 0.9 gestation) as compared to newborn ( 2 day old) hearts $(10,11)$.

The objective herein was to characterize the interactions of glucose and lactate as energy substrates in late fetal and newborn hearts.

\section{MATERIALS AND METHODS}

Animals. Fetal ( 0.9 gestation) and neonatal piglets ( 2 days old) were obtained from local breeders. Pregnant sows or neonatal piglets were delivered to the animal facility. Subsequently, fetal piglets were delivered from sows by hysterotomy and handled as previously described (11). Fetal piglets were used within $4 \mathrm{~h}$ of hysterotomy, while neonatal piglets were used within $8 \mathrm{~h}$ of receipt.

Perfusions. Hearts were removed quickly, chilled in a saline ice bath, and suspended in a perfusion system designed to study metabolism in isolated piglet hearts as previously described in detail (9). Briefly, fetal or newborn pigs were heparinized ( $\mathrm{Na}$ heparin, $40 \mathrm{mg} / \mathrm{kg}$ body weight ip) and anesthetized (Na pentobarbital, $40 \mathrm{mg} / \mathrm{kg}$ body weight ip). Hearts were then removed and briefly perfused via the aorta with a defined medium (KrebsHenseleit bicarbonate buffer, $\mathrm{pH} 7.4$, supplemented with $5 \mathrm{mM}$ glucose and $0.5 \%$ BSA) in a retrograde manner.

Recirculating perfusions were then conducted at $39^{\circ} \mathrm{C}$ for 30 60 min with substrates as indicated in Figures $1-4$ and Table 1. In hearts perfused under working conditions, buffer was infused into the right atrium via the inferior vena cava and was ejected by both ventricles of the heart at controlled pressure (mean arterial pressure $=55 \mathrm{~mm} \mathrm{Hg}$ ) as has been extensively described in previous reports $(9-11)$; cardiac outputs were measured by briefly allowing flow from the heart to enter a graduated cylinder. Retrograde perfusions were performed with cannulation of both the aorta and pulmonary artery in order to provide a work load for both the right and left ventricles. Perfusion pressure was maintained at $60 \mathrm{~mm} \mathrm{Hg}$.

Oxygenation was provided for working and retrograde perfusion by continuously bubbling buffer with a mixture of $95 \%$ $\mathrm{O}_{2}: 5 \% \mathrm{CO}_{2}$. Insulin $(100 \mu \mathrm{U} / \mathrm{ml})$ was also included during all perfusions. Aliquots of perfusion buffer were removed at 5- to 10 -min intervals to monitor changes in metabolite (glucose and lactate) levels during the course of the perfusions. These samples were stored at $-20^{\circ} \mathrm{C}$ until assayed. At the conclusion of the perfusions, hearts were immediately frozen by compression be- 
tween the metal plates of Wollenberger tongs precooled in liquid nitrogen. Frozen hearts were stored at $-70^{\circ} \mathrm{C}$ until assayed.

Determinations of metabolic activity. Oxygen consumption rates of perfused hearts were determined from differences in oxygen tension across the heart (difference between inflow to aorta/pulmonary artery and effluent from inferior vena cava) as previously described (9). Glucose utilization was determined by the production of ${ }^{3} \mathrm{H}_{2} \mathrm{O}$ from $\mathrm{D}-\left[2-{ }^{3} \mathrm{H}\right]$ glucose (New England Nuclear Corp., Boston, MA) (12). Buffer lactate concentrations were determined spectrophotometrically from reduction of NAD in the presence of lactate dehydrogenase (13). Aliquots of recirculating buffer $(2-3 \mathrm{ml})$ were removed from the main reservoir at 5- to 10-min intervals during perfusions to determine the concentration of ${ }^{3} \mathrm{H}_{2} \mathrm{O}$ and lactate present. Linear regression analysis of the data was subsequently performed to yield rates of glucose utilization and lactate production or uptake.

Glucose utilization was represented by the amount of ${ }^{3} \mathrm{H}_{2} \mathrm{O}$ accumulated, reflecting uptake and phosphorylation of $\mathrm{D}-\left[2-{ }^{3} \mathrm{H}\right.$-]glucose. Lactate production (represented as negative uptake in graphs) was determined from the net rate of lactate accumulation in the recirculating buffer. Decreasing buffer lactate concentration was interpreted to indicate net uptake by the heart. Herein, the terms uptake and utilization, when referring to glucose and lactate, indicate net changes in glucose or lactate concentrations measured in the perfusion buffer.

Determinations of tissue metabolite concentrations. ATP, CP, and glycogen concentrations in myocardial tissue were determined in extracts of frozen heart tissue. ATP and CP were measured spectrophotometrically in neutralized, PCA extracts ( 1 $\mathrm{g}$ wet wt heart tissue $/ 4.0 \mathrm{ml} 6 \% \mathrm{PCA}$ ) using the methods of Jaworek and Welsch (15) and Heinz and Weisser (16), respectively. Glycogen content was determined as glucose equivalents in homogenates following acid hydrolysis of $\mathrm{KOH}$ digests of heart tissue (300-400 mg wet wt/1 ml KOH) (17).

Statistical analysis. Data are presented as means \pm 1 SEM. Numbers referred to as $n$ in Table 1 or inscribed at the base of bars in the Figures indicate the number of hearts or animals evaluated for the given parameter. Comparisons between groups consisted of one-way analysis of variance, with differences being considered significant at $p<0.05$.

\section{RESULTS}

The general physical characteristics of fetal and neonatal piglets used in this investigation were similar. Body weights and heart weights of late fetal and early newborn animals used in working heart (antegrade) perfusion experiments showed no significant differences as a function of age (Table 1). In addition, retrograde perfusions with varying concentrations of lactate were performed with a group of 2-day-old piglets. Body weights (1.063 $\pm 0.041 \mathrm{~kg}, n=18)$ and dry heart weights $(1.21 \pm 0.07 \mathrm{~g})$ of these animals were comparable to those of piglets used in antegrade perfusion experiments (Table 1).
Similarly, measurements of physiological parameters disclosed no differences among the hearts studied. CVO was similar for working hearts perfused under the conditions described above (Table 1). In addition, ATP and CP concentrations in a group of working hearts in this series of experiments (19.5 \pm 0.5 and $20.5 \pm 0.9 \mu \mathrm{mol} / \mathrm{g}$, respectively, $n=18$ ) were similar to those previously reported $(10,12)$. ATP and CP in retrograde perfused hearts were slightly higher; $23.5 \pm 1.8(n=13)$ and $26.4 \pm 3.1$ ( $n=18) \mu \mathrm{mol} / \mathrm{g}$, respectively.

Differences in tissue glycogen concentrations were not detectable between the different perfusion groups. Mean tissue glycogen concentrations tended to be higher in fetal hearts; $437 \pm 37(n$ $=25)$ and $314 \pm 19(n=7) \mu \mathrm{mol}$ glucose $\mathrm{eQ} / \mathrm{g}$ for fetal and neonatal hearts, respectively. But this difference is not statistically significant $(p>0.25)$. Glycogen concentrations were unaffected by lactate (Table 1).

Glucose utilization, when glucose was the sole exogenous energy substrate, was similar in fetal and neonatal hearts; $3.34 \pm$ 0.25 and $3.27 \pm 0.22 \mu \mathrm{mol} / \mathrm{g} / \mathrm{min}$, respectively (Fig. 1). In the presence of lactate $(5 \mathrm{mM})$, glucose uptake was reduced to 0.81 \pm 0.08 and $1.03 \pm 0.16 \mu \mathrm{mol} / \mathrm{g} / \mathrm{min}$ for fetal and neonatal hearts, respectively. Suppression of glucose uptake seemed slightly greater in fetal hearts, 76 versus $68 \%$ (Fig. 1).

When glucose was the only carbohydrate substrate provided to hearts undergoing working perfusion, lactate production was observed in both fetal $(2.82 \pm 0.32 \mu \mathrm{mol} / \mathrm{g} / \mathrm{min})$ and newborn $(1.76 \pm 0.33 \mu \mathrm{mol} / \mathrm{g} / \mathrm{min}$ ) hearts (Fig. 2). Lactate production was greater in fetal hearts as compared to newborn hearts. In the presence of lactate $(5 \mathrm{mM})$, net lactate uptake was observed in both fetal and newborn hearts (Fig. 2). Under these conditions, lactate uptake was slightly greater in fetal hearts; mean uptakes $=6.27$ (fetal) and 4.89 (neonatal) $\mu \mathrm{mol} / \mathrm{g} / \mathrm{min}$ (Fig. 2).

Because of the well-established decline in serum lactate concentration in neonates shortly after birth (18), uptake of lactate at lower concentrations was examined in newborn animals. Lactate uptake by the newborn heart was found to be directly dependent on buffer lactate concentration. When lactate was provided in concentrations as low as $0.5 \mathrm{mM}$ in retrogradeperfused hearts, there was considerable suppression of glucose uptake. This suppression tended to be progressive with increasing lactate concentration (Fig. 3). Lactate suppression of glucose utilization occurred even before lactate utilization could be demonstrated. At $0.5 \mathrm{mM}$, lactate production could still be demonstrated, although it was significantly less $(p<0.025)$ than that occurring in the absence of lactate. However, at lactate concentrations exceeding $1 \mathrm{mM}$, lactate utilization was observed which increased proportional to the change in exogenous lactate concentration. Perfusions in fetal hearts at lower lactate concentrations were not performed. The patterns demonstrated at 0 and 5 $\mathrm{mM}$ lactate concentrations were sufficiently similar between fetal and newborn hearts that such an investigation would yield little more substantive information.

Table 1. Body and heart weights, CVO, oxygen consumption, and glycogen content of isolated, working perfused pig hearts

\begin{tabular}{|c|c|c|c|c|c|c|c|}
\hline Age & $\begin{array}{l}\text { Perfusion } \\
\text { conditions }\end{array}$ & $n$ & $\begin{array}{c}\text { Body wt } \\
(\mathrm{kg})\end{array}$ & $\begin{array}{l}\text { Dry heart wt } \\
\text { g [\% dry]* }\end{array}$ & $\begin{array}{c}\mathrm{CVO} \\
(\mathrm{ml} / \mathrm{min} / \mathrm{kg} \text { body } \mathrm{wt})\end{array}$ & $\begin{array}{c}\text { Oxygen } \\
\text { consumption } \\
(\mu \mathrm{mol} / \mathrm{min} / \mathrm{g} \text { dry heart })\end{array}$ & $\frac{\begin{array}{c}\text { Glycogen } \\
\mu \text { mol glucose eQ }\end{array}}{\mathrm{g} \text { dry heart }}$ \\
\hline \multirow[t]{2}{*}{0.9 gestation } & Glucose, $5 \mathrm{mM}$ & 17 & $0.93 \pm 0.03$ & $\begin{array}{r}1.02 \pm 0.05 \\
{[11.4 \pm 0.2]}\end{array}$ & $177 \pm 16$ & $\begin{array}{c}17.4 \pm 1.0 \\
(n=8)\end{array}$ & $441 \pm 34$ \\
\hline & $\begin{array}{l}\text { Glucose, } 5 \mathrm{mM} \\
\text { and lactate } 5 \\
\mathrm{mM}\end{array}$ & 18 & $1.11 \pm 0.06$ & $\begin{array}{c}1.20 \pm 0.08 \\
{[11.5 \pm 0.2]}\end{array}$ & $\begin{array}{l}185 \pm 15 \\
(n=11)\end{array}$ & $\begin{array}{c}22.3 \pm 1.8 \\
(n=11)\end{array}$ & $432 \pm 22$ \\
\hline \multirow[t]{2}{*}{$\begin{array}{l}2 \text { days after } \\
\text { birth }\end{array}$} & Glucose, $5 \mathrm{mM}$ & 6 & $0.97 \pm 0.12$ & $\begin{array}{r}1.05 \pm 0.13 \\
{[11.2 \pm 0.3]}\end{array}$ & $201 \pm 17$ & $\begin{array}{c}21.5 \pm 0.9 \\
(n=6)\end{array}$ & $306 \pm 11$ \\
\hline & $\begin{array}{l}\text { Glucose, } 5 \mathrm{mM} \\
\text { and lactate, } 5 \\
\mathrm{mM}\end{array}$ & 8 & $1.00 \pm 0.07$ & $\begin{array}{r}1.20 \pm 0.13 \\
{[11.4 \pm 0.3]}\end{array}$ & $\begin{array}{l}160 \pm 18 \\
(n=3)\end{array}$ & $\begin{array}{c}21.4 \pm 2.3 \\
(n=3)\end{array}$ & $320 \pm 15$ \\
\hline
\end{tabular}

* Percentage of total heart weight that remains after dessication. 


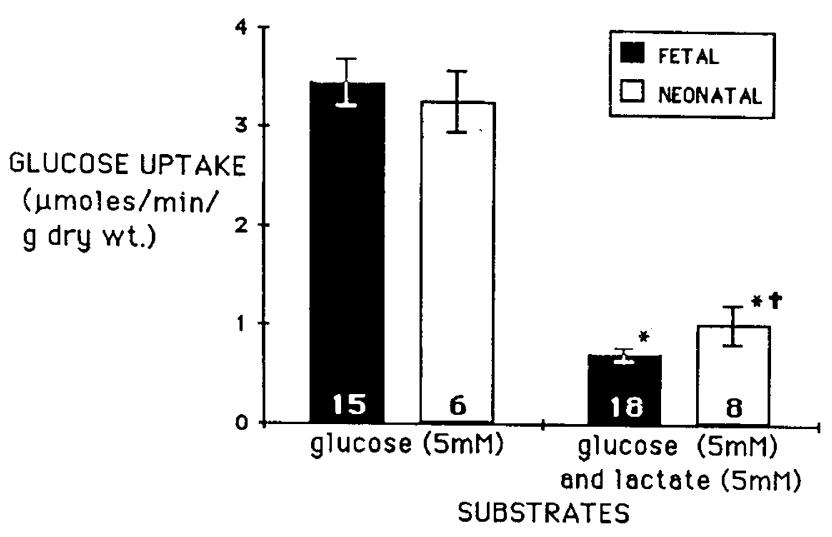

Fig. 1. Glucose uptake by working, perfused fetal and newborn hearts. These data reflect net rates of ${ }^{3} \mathrm{H}_{2} \mathrm{O}$ accumulated in perfusion buffer from myocardial uptake of $\mathrm{D}-\left[2-{ }^{3} \mathrm{H}\right]$ glucose as determined by linear regression. ${ }^{*} p<0.05$ compared to perfusion with glucose alone. $\dagger p<0.05$ compared to fetal hearts under the same conditions.

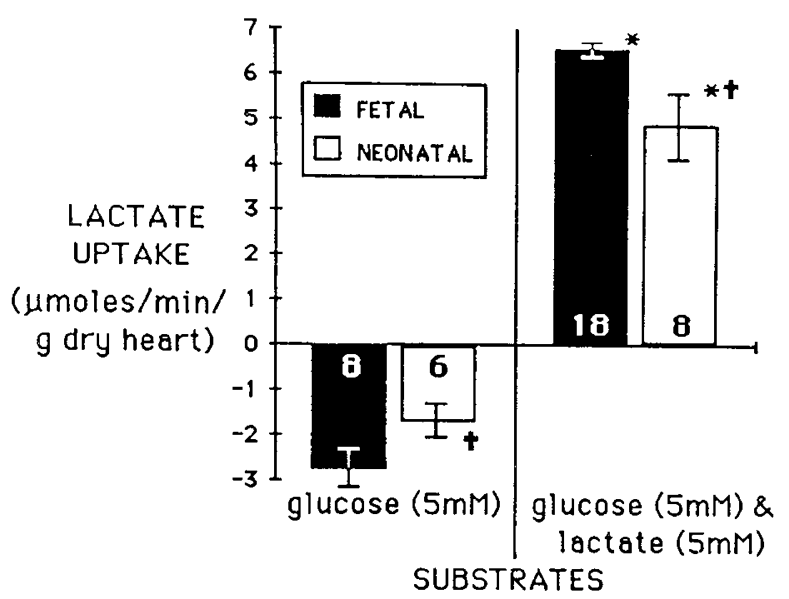

Fig. 2. Lactate uptake by working, perfused fetal and newborn hearts. Net rates of change in buffer lactate concentration as determined by linear regression analysis are shown. Negative lactate uptake represents net rates of lactate production as reflected by increasing lactate concentrations over the perfusion period. Positive lactate uptake denotes net reduction in buffer lactate concentrations throughout perfusions. ${ }^{*} p<$ 0.01 compared to perfusion with glucose alone. $\dagger p<0.05$ compared to fetal hearts under the same conditions.

Oxygen consumptions by retrograde-perfused hearts (13.4 \pm $1.2 \mu \mathrm{mol} / \mathrm{min} / \mathrm{g}$ dry heart, $n=13$ ) were lower than those of hearts perfused under working conditions, since energy requirements are greater to eject fluid in an antegrade (working) fashion. The correlation between lactate concentration and lactate utilization is nevertheless readily apparent. Hearts perfused under working conditions with $5 \mathrm{mM}$ lactate and $5 \mathrm{mM}$ glucose accentuate this relationship, demonstrating that the increased energy needs of working perfusion were supported by increased lactate, rather than glucose, utilization (Fig. 3).

When glucose was supplied as the sole exogenous substrate to fetal or newborn hearts, utilization of exogenous glucose, when corrected for lactate production, accounted for only $60-75 \%$ of total oxygen consumption (Fig. 4). When lactate was present in the buffer, its uptake could account for up to $90 \%$ of oxygen consumption, even in the presence of physiological concentrations of glucose and a high concentration of insulin. Total oxygen consumption in fetal hearts perfused in the presence of $5 \mathrm{mM}$ concentrations of both glucose and lactate $(22.3 \pm 1.8 \mu \mathrm{mol} / \mathrm{g} /$ min) appeared slightly higher than in fetal hearts perfused with

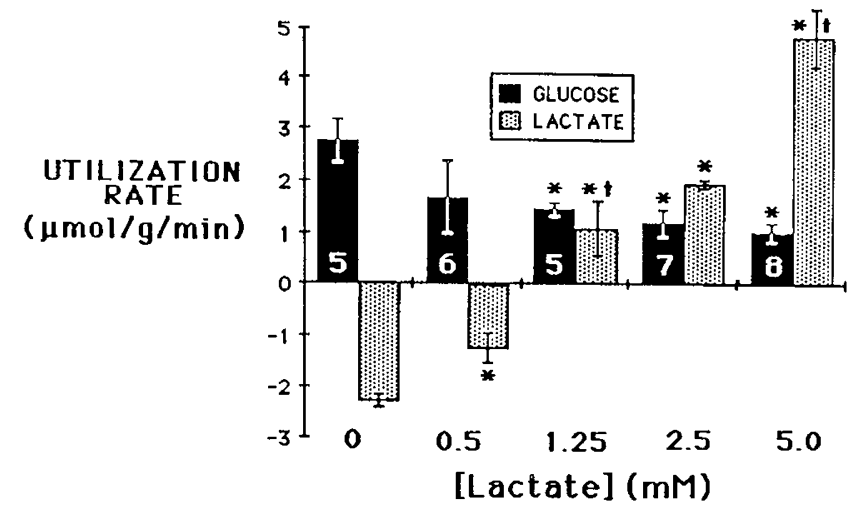

Fig. 3. Glucose and lactate uptake by newborn hearts with varying lactate concentrations. Hearts were retrograde perfused except those perfused with $5.0 \mathrm{mM}$ lactate (working hearts). Net glucose utilization rates denote rates of increased ${ }^{3} \mathrm{H}_{2} \mathrm{O}$ accumulation during perfusions. Net lactate utilizations are represented as negative rates in instances in which there was net lactate accumulation in the buffer during perfusions. Net lactate utilizations are shown as positive rates where net lactate concentrations decreased during perfusions. ${ }^{*} p<0.05$ compared to 0 $\mathrm{mM}$ lactate. $\nmid p<0.05$ compared to the previous (next lower) lactate concentration.

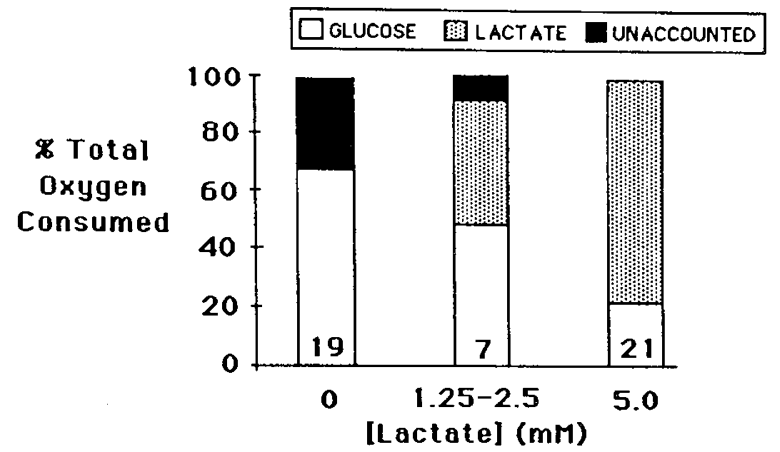

Fig. 4. Percentage of oxygen consumption accountable by glucose and lactate utilization in fetal and newborn hearts. The data represented are the summed results of both fetal and newborn hearts. Absolute oxygen consumptions are indicated in the text and Table 1. Calculations:

$\% 0$ consumption attributable to glucose utilization

$$
=\frac{(\text { glucose utilization } \times 6)-(\text { lactate production } \times 3)}{\text { oxygen consumption }} \times 100
$$

$\% 0$ consumption attributable to lactate utilization

$$
=\frac{(\text { lactate uptake } \times 3)}{\text { oxygen consumption }} \times 100
$$

glucose as the sole substrate $(17.4 \pm 1.0 \mu \mathrm{mol} / \mathrm{g} / \mathrm{min})$, but this difference does not achieve statistical significance. The patterns of oxygen and substrate utilization were very similar between fetal and newborn animals (Table 1).

\section{DISCUSSION}

The findings herein suggest that lactate is a prime source of metabolic energy for the fetal heart. Newborn and late fetal pig hearts are capable of utilizing lactate in quantities sufficient to account for the majority of oxygen consumption when lactate and glucose are provided at physiological concentrations. Net uptake of lactate by the immature pig heart was observed throughout the physiological range. In addition, when lactate was supplied in the perfusion medium with glucose at concentrations characteristically seen in fetal plasma, glucose uptake 
was markedly suppressed. Moreover, glucose uptake, when corrected for lactate production, was not sufficient to account for all of metabolic energy requirements, even when glucose was provided as sole substrate in the presence of insulin. Many of these findings contrast with the traditional impression that the energy needs of the fetal heart are met using glucose as the critical substrate (19).

A previous study (10) of lactate uptake using isolated, perfused working newborn pig hearts indicated that myocardial oxidation could be supported with lactate as the sole substrate. However, in that study, lactate concentrations $(20 \mathrm{mM})$ exceeded physiological concentrations and glucose was not present. The present observations indicate that extensive lactate utilization by fetal and newborn hearts occurs at concentrations approximating those seen under physiological conditions.

An extensive capacity to utilize lactate as an energy substrate has been observed previously in studies of myocardial oxygen consumption and substrate utilization in intact fetal lambs in utero. These studies disclosed a large net uptake of lactate sufficient to account for the majority of fetal oxygen demands (5), even under mildly hypoxemic conditions (20). The extensive oxidative capacity of fetal myocardium is also supported by experiments on fetal rabbit and lamb hearts which indicate that, although oxidation of some fatty substrates is reduced in fetal heart mitochondria, oxidation of most substrates during late gestation equal or exceed that observed in mitochondria isolated from adult hearts $(21,22)$.

Previous studies using various models, including perfused hearts, have effectively demonstrated an increased tolerance for hypoxia and enhanced glycolytic capacity in fetal hearts (12). The observation that lactate production was slightly greater in fetal as compared to newborn hearts (Fig. 2) when no exogenous lactate was provided may be consistent with an enhanced capacity for glycolysis in fetal hearts. The previous studies, however, were not designed to investigate the role of glycolysis in the immature heart under conditions of adequate oxygenation and physiological work, nor did they investigate the capacity of these hearts to oxidize lactate when available in concentrations encountered in the circulation during life. The present findings suggest that glycolysis is not markedly increased in fetal hearts supporting a normal workload with adequate oxygenation.

The preference of the adult myocardium for lactate and pyruvate over glucose has long been recognized (23). The data reported herein demonstrate a similar preference for 3-carbon carbohydrates in late fetal and newborn hearts. While some studies in late fetal animals have shown a pattern of lactate dehydrogenase isoenzymes favoring anaerobic glycolysis (24), and a diminished capacity to transport reducing equivalents across the inner mitochondrial membrane (25), the findings of this study indicate that these enzyme systems are well-developed and functional in the late fetal pig heart and function in a manner similar to the adult.

The exact mechanism by which lactate suppresses glucose utilization in the hearts of either adult or immature hearts was not determined in this investigation. In contrast to the liver or kidney, the heart does not possess a significant capacity for gluconeogenesis (19), so glucose is not preserved through its synthesis. Since lactate is not known to directly alter membrane permeability to glucose and did not appear to significantly stimulate glycogen synthesis, the most important mechanism by which lactate alters glucose utilization appears to be by suppressing glycolysis through inhibition of phosphofructokinase. Phosphofructokinase is a complex allosteric enzyme subject to a variety of modulating influences, including $\mathrm{pH}, \mathrm{ATP}$, and citrate (26). Relatively recently, fructose 2,6-bisphosphate was shown to be a potentially important regulator of glycolysis through stimulation of phosphofructokinase activity (27). This stimulation was greater in fetal than adult hearts, perhaps as a result of isoenzyme switching which occurs during the perinatal period. Moreover, the fetal enzyme remained active at higher ATP concentrations (26). These differences could affect the degree of inhibition of glucose utilization in the presence of lactate. Phosphofructokinase isoenzyme switching and the impact of lactate on phosphofructokinase regulation in pig myocardium will be an important object of future studies.

Several reports describe a variety of conditions in which tissues produce significant quantities of lactate under fully aerobic conditions $(7,10,28)$. This is thought to represent an important mechanism by which different tissues share a carbon source for ready oxidation. This mechanism has been termed the "lactate shuttle" (28). The data reported herein, and by others, regarding lactate utilization by some fetal organs and by the fetus as a whole (7) may represent another important example of this phenomenon. The placenta, and perhaps other organ systems, might act as a source of lactate, a readily utilized source of metabolic energy, for tissues, such as the heart and brain, with large and critical energy requirements The importance of lactate as an energy source in the brain has been shown in recent studies using brain slices from newborn rats. Compared to glucose and 3-hydroxybutyrate, lactate utilization was exaggerated when lactate was present in physiological concentrations (18). Lactate may also be important to the synthetic activities of the fetus, as indicated by recent studies of fetal calf perirenal adipose tissue which show that lactate is a major substrate for fatty acid synthesis (29).

In summary, the primary sources of metabolic energy in the adult heart are fatty acids. However, fatty acids are available in only very limited quantities in fetal plasma and fatty acid oxidation is very low in fetal tissues. Lactate, on the other hand, is present in higher concentrations in fetal than in adult plasma, and recently has been observed to be generated by the placenta (7). This report supports increasing evidence that the fetal heart in late gestation is not glycolysis-dependent under routine physiological conditions. Lactate, in fact, may be a primary energy substrate in the fetal heart, in a manner analogous to fatty acids in the mature heart, in supplying metabolic energy to this organ.

Acknowledgments. The authors thank Anne Rannels, H. Gregg Schuler, Raymond Fripp, M.D., and Victor Whitman, M.D., for valuable technical assistance, and William Oh, M.D. for valuable discussions during the preparation of the manuscript.

\section{REFERENCES}

1. Ballard FB, Danforth WH, Naegle S, Bing RJ 1960 Myocardial metabolism of fatty acids. J Clin Invest 39:717-723

2. Oram JR, Bennetch SL, Neely JR 1973 Regulation of fatty acid utilization in isolated, perfused rat hearts. J Biol Chem 248:5299-5309

3. Liedtke AJ, Nellis S. Neely JR 1978 Effects of excess free fatty acids on mechanical and metabolic function in normal and ischemic myocardium in swine. Circ Res 43:652-661

4. Warshaw JB 1979 Fatty acid metabolism during development. Semin Perinatol $3: 131-139$

5. Fisher DJ, Heymann MA, Rudolph AM 1980 Myocardial oxygen supply and carbohydrate consumption in fetal lambs in utero and in adult sheep. Am J Physiol 238: (Heart Circ. Physiol. 7):H399-H405

6. Van Duyne CM. Havel RJ 1959 Plasma unesterified fatty acid concentration in fetal and neonatal life. Proc Soc Exp Biol Med 102:599-602

7. Sparks JW, Hay WW Jr, Bonds D, Meschia G 1982 Simultaneous measurements of lactate turnover rate and umbilical lactate uptake in the fetal lamb. $\mathrm{J}$ Clin Invest 70:179-192

8. Comline RS, Silver M 1976 Some aspects of fetal and uteroplacental metabolism in cows with indwelling umbilical and uterine vascular catheters. J Physiol 260:571-586

9. Werner JC, Whitman V. Fripp RR. Schuler HG, Morgan HE 1981 Carbohydrate metabolism in isolated, working newborn pig heart. Am J Physiol 241:E364-E371

10. Werner JC, Whitman V. Vary TC. Fripp RR, Musselman J, Schuler HG 1983 Fatty acid and glucose utilization in isolated, working newborn pig heart. Am J Physiol 244:E19-E23

11. Werner JC. Whitman V, Fripp RR, Schuler HG, Musselman J, Sham R 1983 Fatty acid and glucose utilization in isolated, working fetal pig hearts. A.m J Physiol 245:E19-E23

12. Neely JR, Denton RM. England PJ, Randle PJ 1972 The effects of increased heart work on the tricarboxylate cycle and its interactions with glycolysis on the perfused rat heart. Biochem $\mathbf{J}$ 128:147-159

13. Henry RJ 1968 Clinical Chemistry-Principles and Technics. Harper and 
Row, New York, pp 664-666

14. Kunst A, Draeger B, Ziegenhorn J 1983 D-glucose: UV-methods with hexokinase and glucose-6-phosphate dehydrogenase. In: Bergmeyer J, Grassl M (eds) Methods of Enzymatic Analysis, 3rd ed, Vol VI. Verlag Chemie, Weinheim, pp 163-172

15. Jaworek D, Welsch J 1983 Adenosine-5'-triphosphate: UV-method with phosphoglycerate kinase. In: Bergmeyer J, Grassl M (eds) Methods of Enzymatic Analysis, 3rd ed, Vol VII. Verlag Chemie, Weinheim, pp 340-346

16. Heinz F, Weisser H 1983 Creatine phosphate. In: Bergmeyer J, Grassl M (eds) Methods of Enzymatic Analysis, 3rd ed, Vol VII. Verlag Chemie, Weinheim, pp 507-514

17. Hassid WZ, Abraham S 1957 Chemical procedures for analysis of polysaccharides. In: Bergmeyer HU (ed) Methods of Enzymatic Analysis, 2nd ed, Vol III. Academic, New York, pp 34-37

18. Medina JM 1985 The role of lactate as an energy substrate for the brain during the early neonatal period. Biol Neonate 48:237-244

19. Clarke JB, Clark CM 1982 The growth and metabolism of the developing heart. In: Jones CT (ed) Biochemical Development of the Fetus and Neonate. Elsevier Biomedical Press, New York, pp 185-212

20. Fisher DJ, Heymann MA, Rudolph AM 1982 Fetal myocardial and carbohy- drate metabolism in sustained hypoxemia in utero. Am J Physiol 243:H959H963

21. Werner JC, Whitman V, Musselman J, Schuler HG 1982 Perinatal changes in mitochondrial respiration of the rabbit heart. Biol Neonate 42:208-216

22. Wells RJ, Friedman WF, Sobel BE 1972 Increased oxidative metabolism in the fetal and newborn lamb heart. Am J Physiol 222:1488-1493

23. Neely JR, Morgan HE 1974 Substrate and energy metabolism of heart. Ann Rev Physiol 36:413-459

24. Hinks M, Masters CJ 1966 The ontogenetic variformity of lactate dehydrogenase in feline and cavian tissues. Biochim Biophys Acta 130:458-468

25. Rolph TP, Jones CT, Parry P 1982 Ultrastructural and enzymatic development of fetal guinea pig heart. Am J Physiol 243:H87-H93

26. Bristow J, Bier DM, Lange LG 1987 Regulation of adult and fetal myocardial phosphofructokinase. J Biol Chem 262:2171-2175

27. Hers HG, Van Schaftingen E 1982 Fructose 2, 6-bisphosphate 2 years after its discovery. Biochem J 206:1-12

28. Brooks GA 1986 Lactate production under fully aerobic conditions: the lactate shuttle during rest and excercise. Fed Proc 45:2924-2929

29. Wijayasinghe MS 1986 Glucose, acetate and lactate metabolism in perirenal adipose tissue of fetal and newborn calves. Pediatr Res 20:542-544 